\title{
Draft Deployment of Traction Units with Active Tilting System for Regional and Long-distance Transport on Non-modernized Railway Tracks
}

\author{
Vladimír L'upták ${ }^{1, *}$, Ondrej Stopka ${ }^{1}$, and Karel Jeř́ábek ${ }^{1}$ \\ ${ }^{1}$ Institute of Technology and Business in České Budějovice, Faculty of Technology, Okružní 517/10, \\ 37001 České Budějovice, Czech Republic
}

\begin{abstract}
The paper presents the perspectives of suburban traction units with tilting system particularly in regional transport to decrease the travel times and increase the competitiveness of railway transport. It aims to outline the importance of its use in this mode of transport, especially in the case when the condition of infrastructure is unable to provide higher efficiency possibilities for railway enterprises and investments for tracks optimization are not available or insufficient, i.e. enterprises cannot be more efficient in utilization of classic traction units of conventional design. The paper is focused especially on using traction units with tilting system within a selected regional transport section when analyzing the operational and technical characteristics and comparison of time savings after these units deployment.
\end{abstract}

\section{Introduction}

A travel time of passengers from a boarding station to a destination station is considered the main barrier for a high competitiveness of passengers' railway transportation. This is not due to carrier's ability to provide fast, comfortable and safe transportation only, but also due to infrastructure conditions in which a railway carrier operates. One of these conditions is represented by the maximum track speed which cannot be increased by its reconstruction in many cases due to the current deficiency of economic profitability or natural conditions under which the track is built.

Thus, the deployment of modern fleet (rolling stock) of conventional construction to the operation may not bring a sufficient and desired effect which ultimately cannot contribute to the achievement of intended competitiveness. An entry of tilting units into service in this case represents one option in order to reduce travel times on the railway track section. Due to occurrence of tilting device, train can pass the curves at higher speed, and thus reduce travel times, and at the same time, the comfort level can be increased when traveling [1,2].

* Corresponding author: luptak@mail.vstecb.cz 


\section{General principles of the railway tracks selection}

For the best utilization of tilting units regarding passenger transport, the current tracks should be selected in addition to modernized main corridors which are held in harsh and poor natural conditions and the direction is characterized by many curves. That is why it is possible to increase technical speed of passenger trains in such conditions easily and this step leads to increase of its efficiency and attractiveness $[1,3]$.

Railway tracks are generally divided into five speed zones (see Table 1) expressing the upper track speed limit and its related demands on infrastructure maintenance. As the tilting system can be used only for speed of conventional construction vehicles over $70 \mathrm{~km} . \mathrm{h}^{-1}$ (included), further, there is no need to consider the tracks included in the first speed zone SZ1 [1].

Table 1. The speed zones division. Source: [1]

\begin{tabular}{|l|l|}
\hline Zone & Speed \\
\hline SZ1 & up to $60 \mathrm{~km} \cdot \mathrm{h}^{-1}$ \\
\hline SZ2 & from $60 \mathrm{~km} \cdot \mathrm{h}^{-1}$ to $90 \mathrm{~km} \cdot \mathrm{h}^{-1}$ \\
\hline SZ3 & from $90 \mathrm{~km} \cdot \mathrm{h}^{-1}$ to $120 \mathrm{~km} \cdot \mathrm{h}^{-1}$ \\
\hline SZ4 & from $120 \mathrm{~km} \cdot \mathrm{h}^{-1}$ to $160 \mathrm{~km} \cdot \mathrm{h}^{-1}$ \\
\hline
\end{tabular}

Track speed of each railway track is limited by many factors (criteria) such as [4-8]:

- small curve radius,

- insufficient inclination of outer rail in a curve (superelevation),

- improper outlook conditions for horizon ahead,

- inappropriate length or shape of curve transition (for radius and inclination),

- technical condition and low safety level of switches,

- state of the railway superstructure and substructure, etc.

Thus, the suitability evaluation for deployment of tilting units is required, needs to be done and undergo a thorough analysis of the railway track according to the current standards for the geometric position of the normal gauge tracks.

\subsection{The suitability evaluation for deployment of specific traction units}

Units with tilting system serve especially to shorten travel times without the high costs for upgrading an existing infrastructure. Active tilting devices allow 20 to $30 \%$ travel time savings with higher speed driving along curves at tilting up to $8^{\circ}$ against the level of wheel and tracks contact, or to $6.5^{\circ}$ without the comfort of passengers being decreased [1].

According to the current valid STN EN 736360 [9] for geometric position of normal gauge tracks while assessing the state of infrastructure in terms of deploying the units with tilting system, it is required to perform a thorough analysis of the route based on all the relations arising from strictly injunctive or recommended values. These relations and limits are subject to this standard in which certain principles are selected [8-10]:

- tilting system operates by the speed limit at least $\mathrm{v}_{\mathrm{t}}=70 \mathrm{~km} \cdot \mathrm{h}^{-1}$ in the curves with inclination. In the sections with tracks speed limit less than mentioned above for conventional construction vehicles, it cannot be taken into consideration the increase of speed limit when using the tilting units, 
- to take advantage of tilting system, the value of track inclination in curves needs to be at least $\mathrm{p}=30 \mathrm{~mm}$. In folded curve with an inclination, intermediate transitions should have an inclination difference at least $\Delta \mathrm{p}=30 \mathrm{~mm}$,

- the value of insufficient inclination (the difference between theoretical and actual inclination) for tracks without solid parts is reduced to $\mathrm{I}_{\mathrm{k}}=250 \mathrm{~mm}$,

- the value of insufficient inclination for tracks without solid parts compared to the value of inclination should be at least $I_{k}=3.0 p$ (in the most cramped proportions up to $I_{k}=$ $3.5 \mathrm{p})$

- for the curves without inclination, using the tilting units in higher speed limit than the basic limit cannot be considered,

- in order to take advantage of tilting system, these conditions are required:

- curves with inclination must have the outer transitions,

- folded curves with an intermediate inclination transition must have an intermediate radius transition,

o inclination and radius transitions must have the same proper length,

○ the shape and course of curvature must increase the same way for both inclination and radius transitions,

- outer transitions with a linear increase of curvature and inclination shall comply with requirements of the STN EN 7363 60, the same applies for intermediate transition curves.

Trains with the tilting system allow for a reduction of travel times on such tracks which meet the requirements of standards for increase of the tracks speed, however, mostly thanks to its tilting on the tracks with limiting factor of reaching higher speeds right in a curve. All the train wagons are equipped with an active hydraulic system, partially offsetting the effect of lateral acceleration on passengers when passing through the curves to significantly increase the average speed and convenience of traveling on curved railway tracks $[7,11]$.

\subsection{Application of several principles into the selected railway section Bratislava (main station) - Banská Bystrica}

In order verify the suitability of abovementioned units, and thus, achieve the desired results, the railway section Bratislava main station - Palarikovo - Surany - Zvolen passenger station - Banska Bystrica was used when considering intensive directional disparity in the vast length due to the river Hron $[1,12]$.

Figure 1 depicts an existing static speed (velocity) profile (marked as green), which varies in the range from 70 to $100 \mathrm{~km} \cdot \mathrm{h}^{-1}$ in the section Palarikovo - Banska Bystrica and from 100 to 140 km.h-1 in the section Bratislava main station (hl. st.) - Palarikovo. Static speed profile for considered tilting units (marked as blue), in order to analyze track geometry, represents discontinuous and inefficient progress with frequent alternation of velocity extremes, therefore, it was necessary to create reduced profile (marked as red), which respects the fundamental dynamic options of adhesive rolling stock $[1,12,13]$.

Subsequently, this course can be forwarded for further analysis by specifying the travel dynamic of the unit with tilting system and depicting the curve course (flowchart) of actual speed depending on traveled distance. In this case, the position $\mathrm{km} 0.000$ is the position of station Bratislava main station and $\mathrm{km} 230.200$ represents the position of station Banska Bystrica $[1,14]$.

For such a speed profile, it would be necessary to establish the curve inclinations at this railway track section for three curves with their transitions, and for one curve, in order to increase the projected value of inclination when considering the current length of inclination transitions of curves corresponding to the newly proposed value of inclination (superelevation) $[1,14,15]$. 


\subsection{Comparison of selected indicators}

As for the calculation of new qualitative indicators acquired after implementing the units with tilting system into operation, three basic types of passenger trains of category express train (Ex), long distance fast train (F) and commuter local passenger train (Ps) are proposed, and therefore, existing trains, which are operated under the current timetable regardless of their regularity, are supposed to be deployed [15-17].

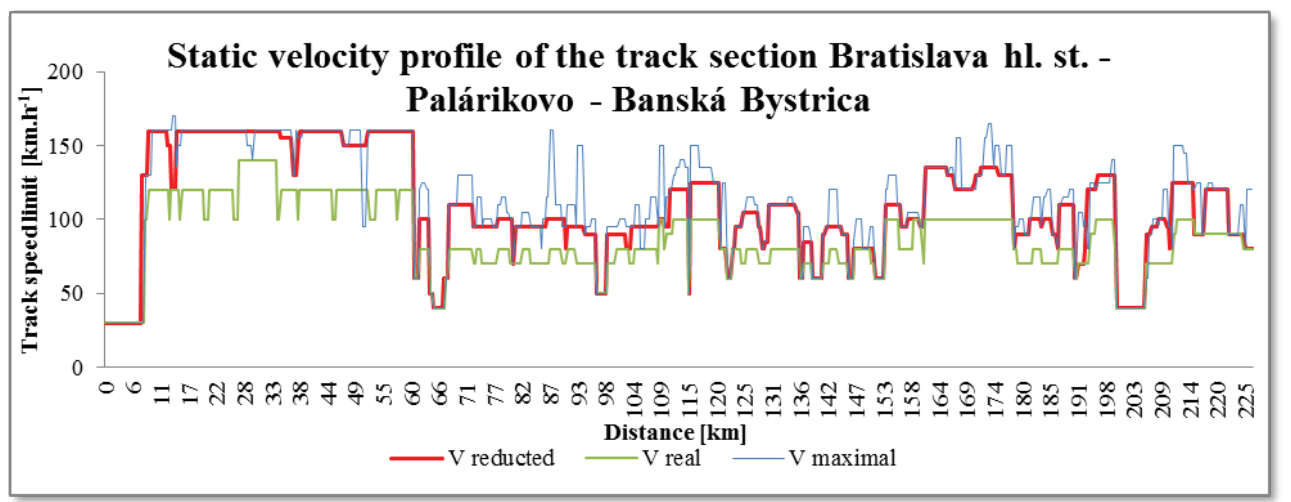

Fig. 1. Static velocity profile of selected railway track section. Source: authors

New travel times were calculated (determined) indirectly using the approximate method of estimation from static speed profile which was selected for the initial orientation detection of time savings due to implementing the tilting units. Travel time under static speed profile of current speeds was calculated and compared with actual travel times of passenger trains under the current timetable due to the dynamic difference coefficient to the static speed profile. The resulting approximate travel time saving for this $223 \mathrm{~km}$ long railway track section is about 20 minutes $[8,12,18,19]$.

Comparison of current and proposed technical speeds for each passenger train category is graphically summarized in following Figure 2.

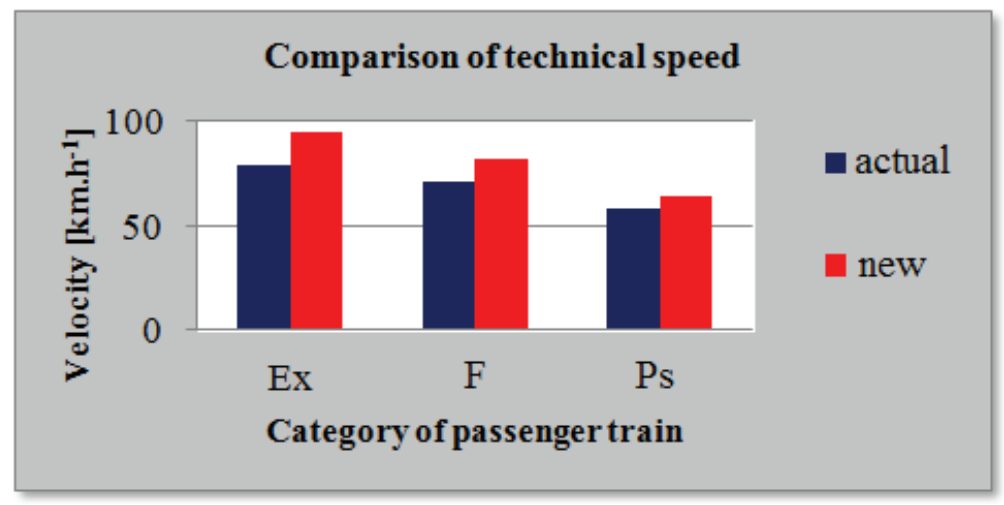

Fig. 2. Comparison of technical speeds. Source: authors

As can be seen in case of the express train (Ex), using tilting units, technical speed increases from current $78.93 \mathrm{~km} \cdot \mathrm{h}^{-1}$ to speed of $94.93 \mathrm{~km} \cdot \mathrm{h}^{-1}$. Technical speed of the fast train (F) also increases from original $70.47 \mathrm{~km} . \mathrm{h}^{-1}$ to speed of $81.87 \mathrm{~km} \cdot \mathrm{h}^{-1}$, and as for the local passenger train (Ps), technical speed increases the from original $57.79 \mathrm{~km} \cdot \mathrm{h}^{-1}$ to speed of $64.03 \mathrm{~km} \cdot \mathrm{h}^{-1}$. 
In regard to sectional travel speeds (technical speed with respect to delay times) of passenger trains, it is the similar scenario in terms of deploying the tilting units (see Figure 3) $[8,12]$.

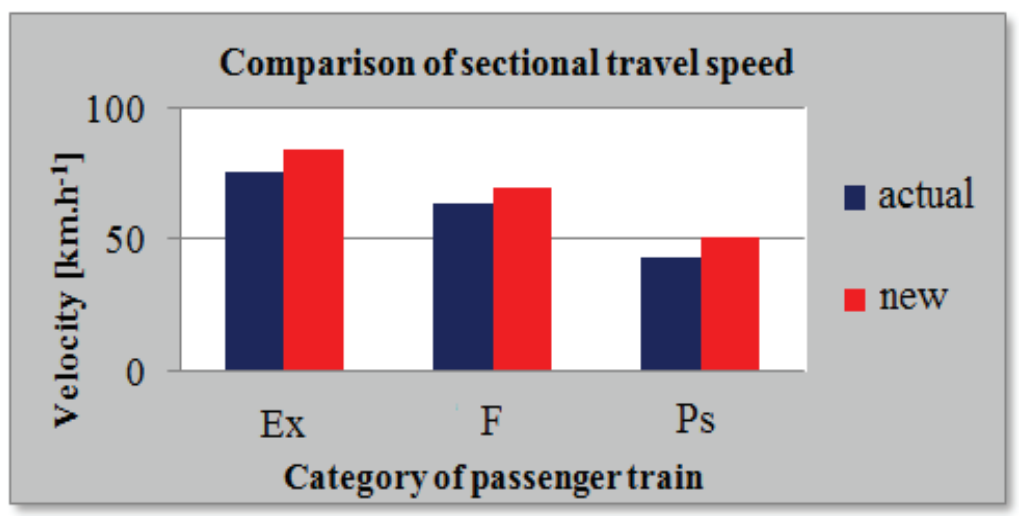

Fig. 3. Comparison of sectional travel speed. Source: authors

As can be seen in case of the express train (Ex), deployment of tilting units improves its sectional travel speed from current $75.48 \mathrm{~km} \cdot \mathrm{h}^{-1}$ to speed of $84.01 \mathrm{~km} \cdot \mathrm{h}^{-1}$. Sectional travel speed of the fast train (F) also increases from original $63.36 \mathrm{~km} \cdot \mathrm{h}^{-1}$ to speed of 69.69 $\mathrm{km} \cdot \mathrm{h}^{-1}$, and regarding the local passenger train (Ps) the sectional travel speed increases from original $43.43 \mathrm{~km} \cdot \mathrm{h}^{-1}$ to speed of $50.78 \mathrm{~km} \cdot \mathrm{h}^{-1}$.

\section{Conclusion}

Performing these analyzes concerning railway track section Bratislava main station Banská Bystrica, it was found that it is likely to deploy regional tilting units to the operation on given track in the vast majority of its length. For their deployment, it would be necessary to make some low-cost steps in order to adjust the railway infrastructure. With the approximate method of estimating the travel time savings, it was found an indicative shortening the express train travel time (Ex) approx. 20 minutes which represents a fundamental value for increasing competitiveness compared to other transport modes within passenger transport $[8,20,21]$.

After deployment of traction units with active tilting system, it leads to greater flexibility of passenger carriers which might significantly compete to road transport, not only by shortening driving (travel) times, but also by increasing the comfort and competitive prices and services $[12,22]$.

Implementation of such a measure would have a beneficial effect not only from a society-wide point of view, but also in terms of emerging railway transport standards.

This paper is supported by the research project "From horse-drawn railway to intermodal transport" within Visegrad Fund.

\section{References}

1. V. Zitricky, J. Gašparík, L. Pečený, Transport Problems 10, Special Edition 2015, 5972 (2015)

2. L. Bartuška, L. Černá, J. Daniš, Naše more 63, 3, 93-97 (2016) 
3. E. Brumercikova, B. Bukova, F. Brumercik, Transport Means - 20th International Scientific Conference on Transport Means, 745-750 (Juodkrante, Lithuania, 2016)

4. B. Abramovic, Promet-Traffic \& Transportation 25, 2, 191-192 (2013)

5. K. Giannakos, Engineering Structures 122, 296-309 (2016), DOI: 10.1016/j.engstruct.2016.04.058

6. K.F. Li, W.N. Liu, Z.W. Han, Z.Z. Wu, Proceedings of the Institution of Mechanical Engineers Part F, Journal of rail and rapid Transit 229, 7, 798-814 (2015), DOI: 10.1177/0954409714521801

7. S.G. Lee, International Conference on Control, Automation and Systems 1-4, 12291232 (Seoul, South Korea, 2008)

8. J. Lalinska, J. Gasparik, D. Sipus, Logi - Scientific Journal on Transport and Logistics 8, 1, 74-81 (2017), DOI:10.1515/logi-2017-0009

9. STN 73 6360. Geometric position and track configuration of the normal railway tracks gauge (Geometrická poloha a usporiadanie kolaje železničných dráh normálneho rozchodu) (1999)

10. V. Zitricky, L. Cerna, B. Abramovic, Procedia Engineering 192, 994-999 (2017), DOI: 10.1016/j.proeng.2017.06.171

11. H.Y. Kim, J.H. Lee, S.H. Han, N.J. Lee, B.T. Kim, C.G. Kang, Proceedings of the Institution of Mechanical Engineers Part F, Journal of rail and rapid Transit 231, 3, 370-378, (2017), DOI: 10.1177/0954409715627841

12. L. Peceny, J. Gasparik, V. Gaborova, ICTTE - 3rd International Conference on Traffic and Transport Engineering, 462-466 (Belgrade, Serbia, 2016)

13. M. Weiszer, G. Fedorko, V. Molnar, CLC 2013 - Carpathian Logistics Congress, 330335 (Krakow, Poland, 2014)

14. O. Havlena, M. Jacura, T. Javořík, M. Svetlík, L. Týfa, Transport Problems 9, 4, $97-$ 104 (2014)

15. M. Halas, J. Gasparik, L. Peceny, Logi - Scientific Journal on Transport and Logistics 4, 2, 28-38 (2013)

16. Z. Cujan, G. Fedorko, Open Engineering 6, 426-431 (2016), DOI:10.1515/eng-20160057

17. T. Kalina, M. Jurkovic, H. Binova, B. Gardlo, Communications: Scientific Letters of the University of Zilina 18, 2,26-29 (2016)

18. M. Chovancova, V. Klapita, Transport Means - 20th International Scientific Conference on Transport Means, 112-116 (Juodkrante, Lithuania, 2016)

19. J. Vrabel, J. Jagelcak, J. Zamecnik, J. Caban, TRANSBALTICA 2017 - Transportation Science and Technology: 10th International Scientific Conference, 89-99 (Procedia Engineering 187, Vilnius Lithuania, 2017), DOI: 10.1016/j.proeng.2017.04.354

20. J. Siroky, Communications: Scientific Letters of the University of Zilina 10, 3, 19-25 (2008)

21. M. Halas, V. Zitricky, P. Blaho, Logi - Scientific Journal on Transport and Logistics 4, 1, 53-62 (2013)

22. R. Kampf, P. Průša, C. Savage, Transport 26, 4, 425-432 (2011), DOI: 10.3846/16484142.2011.635424 